Proceedings of SALT 29: 341-350, 2019

\title{
Negative concord as a marker of empty discourse referents*
}

\author{
Jeremy Kuhn \\ Institut Jean Nicod, CNRS, ENS, \\ EHESS, PSL Research University
}

\begin{abstract}
Negative concord items are restricted to a narrow set of negative environments: roughly, those that are anti-additive or anti-veridical. These environments share the property that they prevent discourse referents from being introduced. Here, I propose that this is the explanatory property of $\mathrm{NC}$ items. NC items are indefinites that flag the fact (in their lexical semantics) that they will fail to introduce a discourse referent. After spelling this out using dynamic semantics, I show that it has number of advantages: (i) It correctly predicts that $\mathrm{NC}$ items must appear under a local anti-veridical operator. (ii) If the presupposition that the DR set is empty is made at-issue, we predict negative uses of NC items: exactly what's attested in fragment answers and non-strict concord languages. (iii) It perfectly unites negative concord with recent analyses of other concord phenomena.
\end{abstract}

Keywords: negative concord, dynamic semantics, split scope

\section{Introduction}

Negative polarity items (NPIs) appear, roughly, in downward entailing environments. Why? Perhaps because in these environments, widening the domain strengthens the utterance (Kadmon \& Landman 1993); perhaps because exhaustifying alternatives doesn't result in contradiction (Chierchia 2013); perhaps because one scopal ordering entails the other (Barker 2018). All these explanations turn out to pick out, roughly, the same contexts.

Negative concord items appear in a smaller set of contexts: roughly, those that are anti-additive (Zwarts 1998) or anti-veridical (Giannakidou 1997). Why? Here, semantic explanations are scarcer (though see Chierchia 2013 for an analysis in terms of exhaustification). But here's one semantic property that these environments have: they prevent discourse referents from being introduced. In (1a), if I say that I didn't see a thing in the room, I cannot use a pronoun to refer to the entity in question, as there is none; likewise for (1b).

* Thank you to Adrian Brasoveanu, Dylan Bumford, Simon Charlow, Milica Denic, Anamaria Fălăuş, Salvador Mascarenhas, Orin Percus, Benjamin Spector, and Hedde Zeijlstra. This work was supported by ERC 324115 (FrontSem, PI: Schlenker) and ANR-17-EURE-0017 (FrontCog).

CC2019 Kuhn 
(1) a. I didn't see a thing in the room. ??It was a table.

b. I went to the party without a date. ??He was wearing a tux.

Here, I propose that this is, in fact, the explanatory property of $\mathrm{NC}$ items. NC items are indefinites that flag the fact (in their lexical semantics) that they will fail to introduce a discourse referent. The very same environments that prevent subsequent discourse reference in (1) are those that license the Italian NC item nessuno in (2).
a. Non ho visto niente. not have seen nothing 'I didn't see anything.'
b. $\mathrm{Ci}$ sono andato sensa nessuno. there have gone without nobody 'I went there without anybody.'

More precisely, I claim that NC items have two components of meaning: (i) the introduction of a discourse referent, like an existential, and (ii) a presupposition, evaluated after introduction, that the extension of the discourse referent is empty. In order to avoid contradiction, these two components of meaning must take split scope around a negative licensor. The denotation of NC nobody in (3a) yields the logical form for the sentence in (3b).
a. $\llbracket$ nobody $_{\mathrm{NC}}^{x} \rrbracket=\lambda c . c(\lambda P .[x] ; P(x)) ; \mathbf{0}_{x}$
b. $\llbracket$ Ed didn't see nobody $\rrbracket=\neg([x] ; \operatorname{see}(x)($ ed $)) ; \mathbf{0}_{x}$

After spelling this out using dynamic semantics, I show that it has number of advantages.

1. It correctly predicts that $\mathrm{NC}$ items must appear under a local anti-veridical operator.

2. If the presupposition that the set of discourse referents is empty is made at-issue, we predict negative uses of NC items: exactly what's attested in fragment answers and non-strict concord languages.

3. It perfectly unites negative concord with recent analyses of other concord phenomena: distributive concord (Henderson 2014) and definite concord (Bumford 2017).

From a general perspective, concord (in all its guises), is a way of redundantly reinforcing the meaning of a logical operator by indicating its effect on the discourse representation. Understand negative concord thus means understanding the dynamics of negative operators. 
Negative concord and discourse reference

\section{Facts to explain}

There are two key properties of negative concord. First, NC items show an (apparently) context-dependent semantics. Sometimes, NC items seem subsidiary to a negative operator, as in (2). In such cases, the simplest analysis is one in which NC items bear a non-negative denotation. Elsewhere, the NC item is the only marker of negation, as in the fragment answers in (4). In such cases, NC items seem to contribute negative force themselves.

(4) Cosa ha visto Maria? Niente.

(Italian)

'What did Mary see? Nothing.'

Second, NC items are characterized by distributional properties. In their 'redundant' uses, are restricted to negative environments; they must be licensed by a sufficiently local negative operator. The NC item in (5) is ungrammatical without negation.

(5) * Ho visto niente.

(Italian)

The two questions to answer are the following: (i) Why do NC items sometimes appear to carry negative force themselves and at other times appear innocently redundant? (ii) What can serve as a licensor of NC, and why do (many instances of) NC items require such a licensor?

\section{Concord, more widely}

Concord describes a phenomenon in which a single logical meaning is expressed morphologically on multiple lexical items. Concord phenomena can be found beyond negative concord. In patterns of distributive concord, multiple words with distributive marking appear innocently in the same sentence, with a single distributive meaning, as seen in (6) and (7).

(6) Chikijujunal ri tijoxela' xkiq'etej ju-jun tz'i'. each(dist) the students hugged one-Dist dog 'Each of the students hugged a dog.'

(Kaqchikel, Henderson 2014)

(7) BOY EACH(dist) CHOOSE-Dist ONE-Dist GIRL.

'The boys each chose one girl.'

(ASL, Kuhn 2017)

In what can be called definite concord, multiple definite articles licensed by a unique tuple of individuals (Haddock 1987). In (8) the definite articles can be used, even if there are multiple rabbits and multiple hats, as long as there is only a single rabbit-hat pair in the containment relation. 
(8) the rabbit in the hat

Recent analyses of distributive and definite concord converge on a semantic analysis in terms of the discourse referents that are introduced. The analysis can be approximated by paraphrase. In patterns of distributive concord, a distributive numeral is equivalent to a plain numeral, plus a postsupposition that the DP refers to a plurality of individuals (Henderson 2014; Kuhn 2017). In patterns of definite concord, the definite article is equivalent to the indefinite article, plus a postsupposition that the DP refers to a unique individual (Bumford 2017). The paraphrases in (9) and (10) provide pseudo-logical forms for (6) and (8).

(9) Each of the students hugged a dog. There are several such dogs.

[Pseudo-LF for (6)]

(10) A rabbit in a hat (there's one such rabbit and one such hat) ate a carrot.

[Pseudo-LF for (8)]

In the paraphrases above, what's underlined is a pre/postsupposition, yielding undefinedness if not met. This has potential consequences on acceptability or on available meanings. For example, (9) ensures a $\forall>\exists$ reading, since $\exists>\forall$ involves a single dog. In general, distributive numerals require a plural licensor. The presupposition in (11) cannot be met, as only a single dog is hugged.

(11) At 2:05, John hugged a dog. \#There are several such dogs.

I propose an exactly analogous analysis for negative concord. A NC item is equivalent to an ordinary indefinite, plus a postsupposition that the extension of the DP is empty. A pseudo-LF of (2a) is provided in (12). Like for distributive concord, the presupposed condition of $\mathrm{NC}$ items necessitates a licensor; without a negative operator, the presupposition in (13) is not satisfied, so (5) is ungrammatical.

(12) I didn't see a thing. There are no such things.

[Pseudo-LF for (2a)]

(13) I saw something. \#There are no such things.

[Pseudo-LF for (5)]

Formally, we will spell out this analysis with split scope and dynamic semantics.

\section{Analysis}

\subsection{Split scope}

In order to avoid a contradictory logical form, the introduction of the discourse referent, and the postsupposition that it is empty must straddle a negative operatorin other words, the NC item must take split scope. Following Cresti (1995) and Charlow (to appear), I allow QR'ed DPs to leave a trace of type $\langle e t, t\rangle$ (call this type $Q)$, yielding a meaning like the one in (15). NC items will be assigned type $\langle Q t, t\rangle$. 
Negative concord and discourse reference

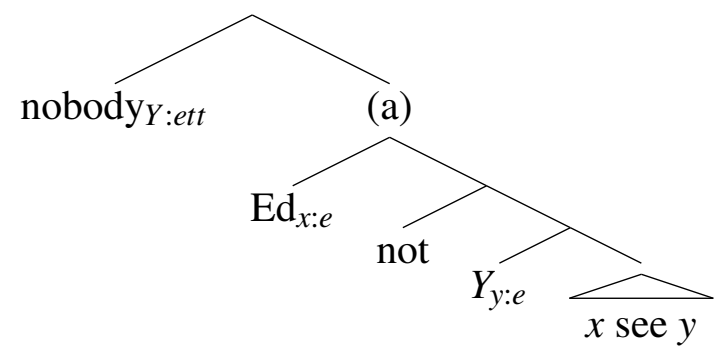

$$
\begin{aligned}
\llbracket(14 \mathrm{a}) \rrbracket & =\llbracket 8_{\langle e t, t\rangle}\left[\operatorname{Ed}\left[6_{e}\left[\operatorname{not}\left[t_{8}\left[7_{e}\left[t_{6} \text { see } t_{7}\right]\right]\right]\right]\right]\right] \rrbracket \\
& =\lambda Q_{\langle e t, t\rangle}[\neg Q(\lambda x[\operatorname{see}(x)(\mathrm{ed})])]
\end{aligned}
$$

\subsection{Dynamics}

Following Groenendijk, Stokhof \& Veltman (1996), states are tuples containing a world and an assignment function. Dynamic updates take a set of states to a set of states. Assignment functions start out with only undefined values (\#). Below are standard dynamic definitions of conjunction, introduction, predication, and negation.

$$
\begin{aligned}
& \varphi ; \psi:=\lambda S . \psi(\varphi(S)) \\
& {[u]:=\lambda S .\left\{t \mid \exists s \in S\left[\exists d\left[t=s^{u \mapsto d}\right]\right]\right\}} \\
& P_{\text {dyn }}\left(u_{1}, \ldots, u_{n}\right):=\lambda S .\left\{t \mid t \in S \wedge P_{\text {stat }}\left(t_{g}\left(u_{1}\right), \ldots, t_{g}\left(u_{n}\right)\right)\left(t_{w}\right)\right\} \\
& \llbracket \operatorname{not} \rrbracket=\neg:=\lambda \varphi \lambda S .\{t \mid t \in S \wedge \varphi(\{t\})=\emptyset\}
\end{aligned}
$$

Recall from the introduction that there are two components to the meaning of negative concord: (i) the introduction of a discourse referent, synonymous to an existential, and (ii) a presupposition that the extension of the discourse referent is empty. Since the first component of meaning-discourse referent introduction-is identical for $\mathrm{NC}$ items and ordinary indefinites, this part of the denotation will be shared. Since NC items are of the higher type $\langle Q t, t\rangle$, NC nobody will be built out of lifted somebody.

$$
\begin{aligned}
& \llbracket \operatorname{somebody}^{x} \rrbracket=\lambda P .[x] ; P(x) \\
& \operatorname{LIFT}\left(\llbracket \operatorname{somebody}^{x} \rrbracket\right)=\lambda c . c(\lambda P .[x] ; P(x))
\end{aligned}
$$

The second component of meaning is a presupposition. By definition, presuppositions check that a property holds across worlds; in case of failure, they return infelicity. This is implemented in (22); the global test ' $\mathbf{0}_{u}$ ' checks that $u$ is empty in all assignments.

$$
\begin{aligned}
\mathbf{0}_{u}:= & \lambda S \cdot \begin{cases}S & \text { iff }\left|S_{g}(u)\right|=0 \\
\# & \text { otherwise }\end{cases} \\
& \text { where } S_{g}(u)=\left\{x \mid \exists s \in S\left[x=s_{g}(u)\right] \wedge x \neq \#\right\}
\end{aligned}
$$


Negative concord items put these two components of meaning together. (23) provides a definition for NC nobody. (24) composes this denotation with the meaning derived via split scope in (15).

$$
\llbracket \text { nobody }_{\mathrm{NC}}^{x} \rrbracket=\lambda c \cdot c(\lambda P \cdot[x] ; P(x)) ; \mathbf{0}_{x}
$$

$$
\llbracket \text { Ed didn't see nobody } \rrbracket=\neg([x] ; \operatorname{see}(x)(\mathrm{ed})) ; \mathbf{0}_{x}
$$

Since NC nobody and somebody differ only the presence of the a postsupposition, we can easily compare the behavior of the two operators. (25) shows the result of evaluating the sentence 'Ed saw somebody' in a context in which only Ed has been mentioned, and we have no information about whether he saw Sue, Ann, or nobody. (26) shows the result of evaluating the sentence 'Ed didn't see somebody' in the same context.

$$
\begin{aligned}
& \llbracket \text { Ed saw somebody }{ }^{y} \rrbracket\left(\left\{\left\langle w_{1}, \begin{array}{cc}
x & y \\
\hline \text { ed } & \#
\end{array}\right\rangle,\left\langle w_{2}, \begin{array}{cc}
x & y \\
\hline \text { ed } & \#
\end{array}\right\rangle,\left\langle w_{3}, \begin{array}{cc}
x & y \\
\text { ed } & \#
\end{array}\right\rangle\right\}\right) \\
& =\left\{\left\langle w_{1}, \begin{array}{cc}
x & y \\
\hline \text { ed } & \text { sue }
\end{array}\right\rangle,\left\langle w_{2}, \begin{array}{cc}
x & y \\
\text { ed } & \text { ann }
\end{array}\right\rangle\right\} \\
& \llbracket \neg \text { Ed saw somebody }{ }^{y} \rrbracket\left(\left\{\left\langle w_{1}, \begin{array}{cc}
x & y \\
\hline \text { ed } & \#
\end{array}\right\rangle,\left\langle w_{2}, \begin{array}{cc}
x & y \\
\hline \text { ed } & \#
\end{array}\right\rangle,\left\langle w_{3}, \begin{array}{cc|c}
x & y \\
\text { ed } & \#
\end{array}\right\rangle\right\}\right) \\
& =\left\{\left\langle w_{3}, \begin{array}{cc}
x & y \\
\hline \text { ed } & \#
\end{array}\right\rangle\right\}
\end{aligned}
$$

The only difference for NC nobody is an additional update with $\mathbf{0}_{y}$, evaluated on the output of the sentence with the existential. The presupposition is satisfied for 'Ed didn't see nobody', since $y$ is undefined in all output contexts in (26). But it is not satisfied for 'Ed saw nobody,' since the values taken by $y$ include Sue and Ann in the output of (25).

\section{Payoff}

\subsection{Locality}

Cross-linguistically, scope-islands are known to block NC item licensing (Déprez 1997; Giannakidou 2000; de Swart \& Sag 2002). In (27), the verb lipame, 'regret' creates a scope island. Giannakidou (2000) shows that the NC item KANENAN cannot be licensed by negation when this scope island intervenes.

* Dhen lipame $\langle$ pu pligosa KANENAN $\rangle$.

Not regret that hurt nobody ${ }_{\mathrm{NC}}$

Desired: 'I don't regret that I hurt anybody.'

(Greek, Giannakidou 2000) 
Negative concord and discourse reference

Under the present analysis, NC items must take split scope around their licensor in order to generate a non-contradictory logical form. By blocking (split) scope, scope islands disallow the necessary configuration.

\subsection{Licensors}

When a discourse referent $x$ is introduced under the quantifier few, the resulting proposition returns some states in which $x$ is not defined, but others in which it is. $\mathbf{0}_{x}$, as a presupposition (i.e., a global test), is not satisfied. The analysis thus correctly predicts that few does not license NC items, as seen in the Italian sentence in (28).

* Poche persone hanno visto nessuno. few people have seen nobody

Zwarts (1998) observes that many licensors of NC items are anti-additive (i.e., functions that satisfy $f(x \vee y)=f(x) \wedge f(y))$. On the other hand, Gajewski (2011) observes that the restrictor of every is an anti-additive environment that nevertheless does not license NC items, as seen in (29). The present analysis captures this fact; van den Berg (1996); Nouwen (2003); Brasoveanu (2008) show that the restrictor of every may indeed introduce discourse referents, as seen in (30).

* Ogni rappresentante di nessuna regione farà parte del gruppo Every representative of no ${ }_{\mathrm{NC}}$ region will-take part of-the group di redazione.

of writing.

Desired: 'Every representative from any region will take part in the drafting team.'

(30) All of my friends who have a plant take good care of it. They each water it every day.

\subsection{Negative uses}

Language often shifts non-at-issue meaning to at-issue meaning (Karttunen 1971; Simons 2007; Beaver 2010). In a dynamic system, these meaning shifts can be modeled using the ACCOMODATE function defined in (31). Interestingly, applying (31) to the denotation of a $\mathrm{NC}$ item results in a negative meaning. The resulting meaning is paraphrased in (32).

$$
\begin{aligned}
& \text { ACCOMODATE }(\psi)=\lambda S .\{t: t \in S \wedge \psi(\{t\}) \neq \#\} \\
& \text { 'Return the maximal context that doesn't yield failure.' }
\end{aligned}
$$


$\llbracket$ nobody $_{\neg} \rrbracket(c)=\operatorname{ACCOMODATE}\left(\llbracket \operatorname{nobody}_{\mathrm{NC}} \rrbracket(c)\right)$

'Return the set of states $t$ such that, if I had updated $\{t\}$ with somebody Xed, then checked for individuals witnessing that proposition, I wouldn't have found any.'

As it turns out, negative uses of NC items are attested in fragment answers and in pre-verbal positions in non-strict concord languages (Ladusaw 1992; Giannakidou 1997; Zeijlstra 2004). Italian is one such non-strict concord language: in (33), the NC item nessuno can appear without sentential negation when it appears before the verb. The meaning of the sentence can be captured using the shifted denotation of nobody in (32).

(33) Nessuno ha telefonato. nobody has called

'Nobody called.'

(Italian)

To account for the restricted distribution of these uses, we can adopt the principle of 'last-resort,' previously proposed as a way to rescue occurrences of NC items that are structurally too high to be licensed by sentential negation. For Zeijlstra (2004), this last-resort option is a silent negative operator. I propose a different last-resort option: accomodation. Unmodified, (33) would result in a presupposition failure. ACCOMODATE returns the maximal context that doesn't result in failure. For (33), this is the context containing only worlds in which nobody called.

\section{Conclusion}

What does concord do? Concord, I have claimed, is a way of redundantly reinforcing the meaning of a logical operator by indicating its effect on the discourse representation. Distributive concord indicates that a discourse referent is a plurality. Definite concord indicates that a discourse referent is unique. Negative concord, I have argued, indicates that a discourse referent is empty. In spelling out this intuition, I have explained why negative concord items can only appear in a specific set of negative environments.

\section{References}

Barker, Chris. 2018. Negative polarity as scope marking. Linguistics and philosophy 41. 483-510. doi:10.1007/s10988-018-9234-2.

Beaver, David. 2010. Have you noticed that your belly button lint colour is related to the colour of your clothing? In R. Bauerle, U. Reyle \& T. E. Zimmermann (eds.), Presuppositions and discourse: Essays offered to hans kamp, 65-99. Oxford, UK: Elsevier. 
Negative concord and discourse reference

van den Berg, Martin. 1996. Some aspects of the internal structure of discourse: the dynamics of nominal anaphora: ILLC, Universiteit van Amsterdam. PhD dissertation.

Brasoveanu, Adrian. 2008. Donkey pluralities: Plural information states vs. non-atomic individuals. Linguistics and Philosophy 3(2). 129-209. doi:10.1007/s10988-008-9035-0.

Bumford, Dylan. 2017. Split-scope definites: Relative superlatives and haddock descriptions. Linguistics and Philosophy 1-45. doi:10.1007/s10988-017-9210-2.

Charlow, Simon. to appear. Post-suppositions and semantic theory. Journal of Semantics.

Chierchia, Gennaro. 2013. Logic in grammar: Polarity, free choice, and intervention, vol. 2 Oxford studies in semantics and pragmatics. Oxford, UK: Oxford University Press.

Cresti, Diana. 1995. Extraction and reconstruction. Natural Language Semantics 3(1). 79-122. doi:10.1007/bf01252885.

Déprez, Viviane. 1997. Two types of negative concord. Probus 9. 103-143. doi:10.1515/prbs.1997.9.2.103.

Gajewski, Jon. 2011. Licensing strong NPIs. Natural Language Semantics 19. 109-148. doi:10.1007/s11050-010-9067-1.

Giannakidou, Anastasia. 1997. The landscape of polarity of items: University of Groningen PhD dissertation.

Giannakidou, Anastasia. 2000. Negative ... concord? Natural Language and Linguistic Theory 18. 457-523. doi:10.1023/A:1006477315705.

Groenendijk, Jeroen, Martin Stokhof \& Frank Veltman. 1996. Coreference and modality. In S. Lappin (ed.), The handbook of contemporary semantic theory, 179-216. Oxford, UK: Blackwell.

Haddock, Nicholas J. 1987. Incremental interpretation and combinatory categorial grammar. In The 10th international joint conference on artificial intelligence, vol. 2, 661-663. Morgan Kaufmann Publishers Inc.

Henderson, Robert. 2014. Dependent indefinites and their post-suppositions. Semantics and Pragmatics 7(6). 1-58. doi:http://dx.doi.org/10.3765/sp.7.6.

Kadmon, Nirit \& Fred Landman. 1993. Any. Linguistics and Philosophy 16(4). 353-422.

Karttunen, Lauri. 1971. Some observations on factivity. Papers in Linguistics 5. 55-69.

Kuhn, Jeremy. 2017. Dependent indefinites: the view from sign language. Journal of Semantics 34(3). 449-491. doi:10.1093/jos/ffx007.

Ladusaw, William. 1992. Expressing negation. In Chris Barker \& David Dowty (eds.), Semantics and Linguistic Theory 2 (SALT 2), 2237-259. Ithaca, NY: Cornell University Press. 
Nouwen, Rick. 2003. Plural pronominal anaphora in context: Dynamic aspects of quantification. Utrecht, Netherlands: Utrecht University PhD dissertation.

Simons, Mandy. 2007. Observations on embedding verbs, evidentiality, and presupposition. Lingua 117. 1034-1056. doi:10.1016/j.lingua.2006.05.006.

de Swart, Henriëtte \& Ivan A. Sag. 2002. Negation and negative concord in romance. Linguistics and philosophy 25. 373-417. doi:10.2307/25001855.

Zeijlstra, Hedde. 2004. Sentential negation and negative concord: University of Amsterdam $\mathrm{PhD}$ dissertation.

Zwarts, Frans. 1998. Three types of polarity. In Fritz Hamm \& Erhard Hinrich (eds.), Plurality and quantification, vol. 69 Studies in Linguistics and Philosophy, 177-238. Dordrecht, Netherlands: Springer. doi:10.1007/978-94-017-2706-8_5.

Jeremy Kuhn

29, rue d'Ulm

Ecole Normale Supérieure

75005 Paris, France

jeremy.d.kuhn@gmail.com 